abdomen. Steevens's Hospital being closed, she was taken into the Mater Misericordiæ Hospital, and seen by Dr. More Madden, the obstetrical physician, who considered the case one for immediate operation, in consequence of the delicate state to which the woman was reduced in a short period and the intense degree of pain caused by the tumour. A few days after her admission the patient was seen in consultation by Dr. More Madden, Dr. Duke, Mr. P. Hayes, and Dr. Boyd, all of whom agreed that the case was one for ovariotomy, the diagnosis being a thinwalled, globular, well-marked multilocular ovarian tumour. The abdomen then measured $431 \mathrm{in}$. in girth. Being close on the menstrual period it was decided not to operate until this should have passed, and it was accordingly postponed antil June 15th, tonics being administered to increase the woman's strength. She was up and going about the ward, but on June 9th she took to her bed, complaining of intense abdominal pain. After some hours the pain was followed by incessant diarrhoea and profuse diuresis, which lasted four days. At the expiration of this period the abdomen was found to have considerably decreased and no trace of the tumour was discernible. The patient was again seen in consultation by the before-mentioned gentlemen, including Dr. Byrne. All concurred that spontaneous rupture of the cyst had taken place, with effusion of the ovarian flluid into the peritoneal cavity, its absorption thence, and evacuation by the bowels and kidneys. After this the patient gradually improved. An examination was made on June 16th. Some fluid was still discernible in the peritoneal cavity, but the abdominal pain and soreness were greatly reduced. To relieve the pain and help the absorption, an ointment made up of extract of belladonna and mercurial ointment was rubbed over the abdomen, and a mixture of iodide of potassium given, which she had been taking some time previously. The patient remained in bed about fourteen days, recovering both health and strength. The abdominal swelling had gone down to $29 \mathrm{in}$. The woman finally left the hospital on July 15th, and was again seen after a week, when she was in excellent health and spirits, being about to take a journey to the country.

\section{ST. JOSEPH'S HOSPITAL, VICTORIA, BRITISH COLUMBIA.}

ANEURYSM OF THE INNOMINATE ARTERY; SIMULTANEOUS LIGATURE OF THE COMMON CAROTID AND SUBCLAVIAN ARTFRIES ; HEMIPLEGIA ; DEATH.

(Under the care of Mr. E. A. Pratgrr.)

S. B- , a Frenchman, aged sixty, applied for advice on Jan. 26th, 1885, giving the following account of himself Family history very good. Has never had any serious illness. Had gonorrhoea years ago, but never had syphilis. Has been a gold miner and has done a great deal of "packing" goods to and from the mines. Two years ago a heavy weigh fell on his chest. Shortly afterwards he noticed a swelling on the right side of the chest, between the first and third ribs. The swelling has gradually increased in size. Feels an oppression when he draws a long breath. Has a cough, which has only existed the last month or two, and expectorates a little bright blood occasionally. When he walks fast or goes upstairs, he experiences a feeling which he describes as "like palpitation of the heart, under the swelling." Sometimes when walking in the street he is seized with dizziness and inability to breathe, and has to catch hold of anything at hand to prevent himself from falling. Complains of constant pain at the back of the right shoulder and in the chest, under the swelling. Has a constant numbness in the right arm and hand, and says the pain is so bad that he is unable to sleep at night.

The patient's condition on examination was as follows:Muscular, but not fat. There is an expansile pulsating tumour extending from the right sterno-clavicular articulation to the second intercostal space. The first and second bones of the sternum and the sternal ends of the corresponding ribs are bulged forwards. A loud rasping bruit is distinctly audible all over the upper part of the right side of the chest. Pulsation in the right radial is hardly perceptible; strong and regular in the left. On pressure being made over the subclavian artery the symptoms are modified. Heart sounds normal. The man was ordered fifteen grains of iodide of potassium three times a day and a low diet. This treatment was continued for some weeks without benefit. At the request of $\mathbf{M r}$. Praeger the patient was carefully examined by Surgeon-Major Harrison, A.M.D., and Staff-Surgeons T. Canning Hickey and J. Lyon, R.N., who concurred in the diagnosis of aneurysm of the innominate artery.

The man was so anxious that operative measures should be adopted for his relief, although the immense risk attending surgical interference was fully explained to him, that with the consent and valuable assistance of the gentlemen above-named, it was determined to ligature the common carotid below the omo-hyoid and the subclavian in the third part of its course. He was accordingly admitted into hospital, and, on March 26th, chloroform having been administered by Dr. Hickey, an incision parallel with the anterior border of the sterno-mastoid was made through the skin and superficial fascia. The deep fascia having been scratched through with the finger-nail, the artery was reached. At this stage the patient vomited, which caused slight delay, but eventually the aneurysm needle, threaded with strong carbolised gut, was passed from without inwards around the artery, and it having been ascertained that nothing but artery was included, the ligature was applied and pulsation in the temporal artery was found to have stopped. Neither the jugular vein nor the pneumogastric nerve came into view. The wound was sponged with carbolised water and drawn together with silver wire sutures. The patient's shoulder being depressed, an incision was then made in the usual way by drawing down the skin and dividing it on the clavicle. While making this incision the patient romited, and two small superficial veins (which it was the intention to avoid) were accidentally cut across, and caused great difficulty in securing them. A second incision was then made upwards at right angles to the first, and the deep fascia having been torn through with the finger-nail, the subclavian artery was felt for, and the aneurysm needle, threaded as before, passed around it, and the ligature applied. Pulsation was found to be wanting in the radial artery. The brachial plexus was felt, but the subclavian vein was not seen. The edges of the wound were brought together with silver wire, and the arm having been enveloped in cotton-wool, the patient was removed to bed. Pulsation in the tumour was hardly perceptible. The patient soon rallied from the shock, and complained of pain in the neighbourhood of the operation wounds only. 9 P.M.: Very feeble pulsation was felt in the right radial, none in the temporal, strong and regular on the left side. Temperature in the left axilla normal, in the right $96^{\circ}$. He was perspiring profusely. A subcutaneous injection of a quarter of a grain of morphia was given.

March 27th.-Slept fairly well, but has been vomiting and retching violently. Temperature normal in both axillæ: Pulsation in tumour very much diminished, no bruit. Pulsation in right radial rather stronger than last night; hardly perceptible in the right temporal.

28th.-Temperature normal in both axillæ. Pulse 92. Very much stronger in the left than in the right radial. Not properly established in the right temporal. Pulsation in the tumour hardly perceptible.

29th.-Temperature normal. Pulse 72. Feeble in left radial; more so in right. Has difficulty in swallowing; complains of pain in his head; cannot protrude his tongue properly; his speech is thick and he appears deaf. Pupils contracted.

30th.-During yesterday the left side of the face became paralysed, and during the night the left side became hemiplegic. Temperature normal. Pulse 84, becoming stronger in the right radial, but not so strong as in the left. Still complains of pain in the head. Is quite conscious; converses sensibly, but with thick utterance.

April 1st.- Operation wounds have healed by first intention; hyperæsthesia of left side.

May 3rd.-Less hyperæsthesia; passing large quantities (several pints) of urine of low specific gravity (1005); acid, no albumen.

Aug. 10th.--The quantity of urine has steadily diminished under ergot. Complete loss of sensibility and motion in the left side.

Feb. 20th, 1886.-Has continued in much the same state; eats and sleeps well; has recovered sensibility, but not power of movement in the left side.

March 10th.-Caught cold a few days ago; had bronchitis, followed by exhaustion, to which he succumbed to-day-a year, less a few days, from the date of operation.

Remarks by Mr. PRAEGER.-1 greatly regret that, owing to a mistake on the part of the hospital porter, no post- 
mortem examination was obtainable. The diagnosis arrived at was that the aneurysm was innominate, possibly subclavioinnominate, but that the aorta was not involved. Judging from the rapidity with which circulation was re-established in the right arm, it is probable that the first part of the subclavian, with the thyroid axis, was abnormally dilated. On several occasions previous to the operation, the patency of the vessels to the brain had been tested by making pressure on the right and left carotids together and singly, and after reading the article, written by Mr. Barwell, on this class of cases, this was considered one suitable for operation. Although the patient subsequently became hemiplegic (probably from failure in re-establishing the cerebral circulation), the symptoms of aneurysm gradually subsided, and there is little doubt that the operation succeeded in prolonging his life.

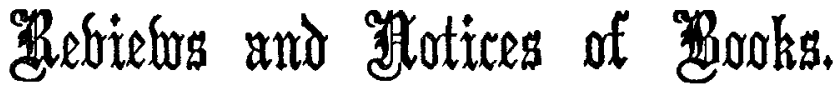

\section{An Introduction to General Pathology. By JoHN BuAND} SutToN, F.R.C.S. London: J. and A. Churchill. 1886.

IN this handsome and well-illustrated volume we have not only to welcome the work of a new writer, but, what is equally gratifying, to receive in it an abundance of new facts added to the pathological store. When, at Mr. Hutchinson's suggestion, the Pathological Society of London undertook to investigate more thoroughly than had ever before been attempted the diseases of animals, and had obtained with this object the co-operation of the Zoological Society, the services of Mr. Bland Sutton were secured, and in the main the facts recorded in the work before us have been gathered by him in the course of his five years' steady and unflagging pursuit of the objects which the Pathological Society had in view. The Transactions of that Society have been enriched by many communications from Mr. Sutton; but we venture to think that this further publication, which embraces so considerable a range, will astonish even the members of the Society, who have already been witnesses of the thoroughness and zeal with which he has pursued his researches. The gist of the contents of the volume was given by the author in his Erasmus Wilson Lectures at the College of Surgeons last spring; but it is needless to say that the topics there treated have received fresh illustration and considerable expansion here. The work is divided into five sections: the first, dealing with aberrations of nutrition, illustrates the subjects of hypertrophy and atrophy, correlation and degeneration; the second treats of inflammation and its results; the third is deroted to the cystomata; the fourth to neoplasms; and the concluding section reviews the subject of evolution as influenced by pathological processes. To adequately treat of such subjects in respect to the animal world, the writer must be as much a naturalist as a pathologist, and undoubtedly the present author presents just this combination. Such chapters as those on correlation and on the cystomata exemplify this, whilst the predominant idea of the work is the explanation of pathological facts by means of the evolution hypothesis.

Although for the most part the work consists of an aggregation of original observations upon facts of pathological interest in the animal world, there are not wanting pages in which the author shows that he possesses to a marked extent that great gift of generalisation which is so essential in the collation and comparison of individual facts. Perhaps the best instance of this is to be found in the chapter upon Inflammation, where Mr. Sutton boldly assigns a rôle to the ubiquitous leucocyte which far outstrips the conception of Cohnheim. For whereas that much-lamented observer and acute thinker was content to attribute the phenomena of inflammation mainly to deterioration of the delicate tissue of the vessel wall, Mr. Sutton, by a skilful use of the most recent discoveries of intercellular digestion and the phenomena of tissue-resorption as observed in the metamorphosis of the amphibian, sees in the white blood-corpuscle an active (we might almost say a combative) body which is stimulated to increase and multiply for the purpose of resenting injury and preventing the intrusion of foreign matter into the living organism. The conception is one which dazzles as much from its simplicity as from the ideas to which it gives rise, opening up suggestions in the direction of explaining the nature of so-called specific inflammatory neoplasms, and capable even of extension into the wider field of all new formations. Great as has been the dignity of the leucocyte hitherto-indeed, its amœbalike characters long since fascinated some naturalists, who endowed it with a special individuality,--it has certainly never been assigned so wonderful a rôle as Mr. Sutton would fain have us admit it to possess. We may nevertheless commend the study of this chapter as one full of suggestiveness to those who desire to extend our notions of pathological processes a little beyond their mostly too confined limits.

The chapters devoted to the Cystomata are full of interesting facts well marshaled. They go far to fill up a distinct lacuna in our knowledge. Indeed, the subject has never been adequately treated hitherto in any English textbook; for Virchow's classical description in his great (but unfinished) work on Tumours is not available to the Englishreading student. Again, thanks to many observers, and largely to the author of this book, very material additions. have been made to the subject, especially as concerns cysts in connexion with the reproductive organs; so that we venture to think that subsequent writers will be under great obligation to him for what he has done in this direction.

As to the chapters on Neoplasms, it must suffice here to say that Mr. Sutton is an ardent adherent to Cohnheim's. doctrine of "tumour-germs," and that he adduces very numerous instances of various kinds of new growth in all varieties of animals which bear largely on that doctrine. Especially to be mentioned are the examples of teratomata, where, again, we find many new paths opened up, and. advantage taken of the knowledge afforded by embryological research. Indeed, the book is one which will well repay careful study; and the fact that it is the product of one of our younger pathologists is encouraging, not only because it is written in the true scientific spirit, but because it is of good augury for many future contributions from the same source.

Il Clima di Roma. Conferenze fatte nella Primavera del 1885, inaugurando l'Istituto d'Igiene Sperimentale della R. Università di Roma. Con una Carta Topografica $\theta$ Geologica dell' Agro Romano, e cinque Tavole illustrative. Por Corrado Tommasi-CRudrit. (The Climate of Rome. Lectures delivered in the Spring of 1885, at the opening of the Institute of Experimental Hygiene in the Roman University. With a Topographical and Geological Map of the Agro Romano, and five illustrative Plates. By Dr. Conrad Tommasi-Crudeli) Rome: Hermann Loescher and Co. 1886.

MEDrCaL climatology has made advances of which the importance could not be better appreciated than by comparing the present work with that published on the same subject by Sir James Clark half a century ago. Dr. TommasiCrudeli comes to his task equipped with accomplishments which were hardly considered as within the medical province in his distinguished predecessor's time. Himself an. original authority in physiology and pathology, he possesses a knowledge of the earth's crust, its flora and its fauna, the waters that permeate it, the winds that sweep it, such as. more than fulfil the Hippocratic ideal. So qualified, he has made a special study of the climate of Rome, and the results of his successive monographs on the subject are revised and condensed in the present volume.

When we talk of the Roman climate we cannot dissociate. the theme from its distinctive characteristic-the malarial 